\title{
The epidemiology of groin injury in senior football: a systematic review of prospective studies
}

Markus Waldén, Martin Hägglund and Jan Ekstrand

\author{
Linköping University Post Print
}

Tweet

N.B.: When citing this work, cite the original article.

Original Publication:

Markus Waldén, Martin Hägglund and Jan Ekstrand, The epidemiology of groin injury in senior football: a systematic review of prospective studies, 2015, British Journal of Sports Medicine, (49), 12.

http://dx.doi.org/10.1136/bjsports-2015-094705

Copyright: BMJ Publishing Group

http://group.bmj.com/

Postprint available at: Linköping University Electronic Press

http://urn.kb.se/resolve?urn=urn:nbn:se:liu:diva-119791 


\section{The epidemiology of groin injury in senior football: a systematic review of prospective studies}

\section{Markus Waldén, 1,2 Martin Hägglund, 2,3 Jan Ekstrand ${ }^{1,2}$}

${ }^{1}$ Division of Community Medicine, Department of Medical and Health Sciences, Linköping University, Linköping, Sweden

${ }^{2}$ Football Research Group, Linköping University, Linköping, Sweden

${ }^{3}$ Division of Physiotherapy, Department of Medical and Health Sciences, Linköping University, Linköping, Sweden

\section{Corresponding author}

Markus Waldén, Division of Community Medicine, Department of Medical and Health Sciences, Linköping University, 58183 Linköping, Sweden

E-mail: markus.walden@telia.com

Twitter: @MarkusWalden, @MHgglund, @JanEkstrand, @frgsweden

Word count: 3018 


\section{ABSTRACT}

Background Groin injuries are troublesome in men's and women's football.

Aim To review the literature on the epidemiology of groin injury in senior football and compare injury occurrence between sexes.

Methods Studies were identified through a search of PubMed, EMBASE, CINAHL and Web of Science, in the reference lists of the selected articles and the authors' bibliographies. The number of injuries, percentage of groin injury from all injuries, and rate of groin injury per $1000 \mathrm{~h}$ were extracted. Exposure and injury data were aggregated across included studies and the absolute difference in groin injury proportion and rate of groin injury were compared between sexes. Risk of bias was assessed using a 5-item checklist.

Results 34 articles met the study criteria and were included. The proportion of groin injury in club-seasonal football was $4-19 \%$ in men and $2-14 \%$ in women. Aggregated data analysis (29 studies) showed a higher relative proportion in men than in women $(12.8 \%$ vs $6.9 \%$, absolute difference $5.9 \%, 95 \% \mathrm{CI} 4.6 \%$ to $7.1 \%$ ). The rate of groin injury varied from $0.2-2.1 / 1000 \mathrm{~h}$ in men and 0.1-0.6/1000 $\mathrm{h}$ in women, and aggregated analysis (23 studies) showed a more than two-fold higher rate in men $(0.83$ vs. $0.35 / 1000 \mathrm{~h}$, rate ratio $2.4,95 \%$ CI 2.0 to 2.9$)$. High risk of bias was identified for participant selection (18 studies), exposure (17 studies), and precision estimate (16 studies).

Conclusions Groin injuries are frequent in senior football, and are more common in men than women. Future research needs to be of higher quality. 


\section{INTRODUCTION}

Football is the world's most popular sport with more than 265 million active players according to the Big Count of the Féderation International de Football Association (FIFA) in 2006.[1] The majority of football players sustain at least one injury causing lay-off from football each season and the vast majority of the injuries are located to the lower extremities.[2,3] Groin injuries, or sometimes referred to as hip and groin injuries, often constitute a diagnostic challenge for the medical practitioner. Whereas the hip joint is anatomically well-defined, the groin area is, by contrast, not unambiguously specified, but usually refers to the junction between the lower abdomen and the anteromedial part of the thigh.

The general rate of injury in football is known to be high, especially during match play, which has been reported repeatedly in different injury surveillance research.[2,3] From collegiate football in the US, it has been reported that the rate of groin injury is higher in males compared with females.[4,5] However, to our knowledge, there is no previously published review that specifically summarises the occurrence of groin injury in senior football. The objective of this paper was therefore to comprehensively review the literature on epidemiology of groin injury in men's and women's senior football, and to compare injury occurrence between sexes. Our hypothesis was that the occurrence of groin injury is higher in male compared with female players. 


\section{METHODS}

This review was prepared and conducted according to the preferred reporting items for systematic reviews and meta-analyses (PRISMA) guidelines (Moher et al., 2009).[6] The review was registered in the PROSPERO International Prospective Register of Systematic Reviews (\#CRD42015016373) before study selection and data extraction.

\section{Literature search}

Potentially eligible studies were identified through a systematic search in the following electronic databases from inception to 26 January 2014: MEDLINE via PubMed, EMBASE, via OVID, CINAHL via Ebesco, and Web of Science. The free-text search term "(football OR soccer) AND (groin inj* OR groin pain)" without any limitations was used in all four databases. One author (MW) carried out the electronic database search in collaboration with two librarians. All citations were imported to EndNote X7 (Thomson Reuters, US) and duplicates were removed by the first author (MW).

\section{Literature screening}

Articles were screened in three steps (title, abstract, and full text) according to pre-determined study criteria. Two authors (MW and MH) skimmed all titles and abstracts and selected potential studies for inclusion independently. Full texts were retrieved and reviewed for articles that clearly met the inclusion criteria or those that could not be explicitly excluded from the title and abstract. In addition, manual searches in the reference lists of the selected articles and the authors' bibliographies were undertaken by the two reviewers in order to identify other potentially relevant studies. Disagreements were resolved via consensus, and, a third author (JE) was to be consulted if no agreement was reached. No hand-search of specific sports medicine journals was performed. 


\section{Inclusion and exclusion criteria}

Articles were included in this review if they met the following criteria: (1) were original level I and II articles with a prospective design (cohort studies, clinical trials, and randomised trials), (2) reported groin injury data in organised senior (adult) football play, (3) had a study period encompassing at least one playing season or national team tournament, (4) defined injury according to medical attention and/or time-loss, and (5) were written in English.

The following articles were excluded from this review: (1) expert opinions, case reports/series, case-control studies, cross-sectional studies and retrospective cohort studies, (2) duplicate publications and multiple studies on the same cohort, where studies were selected based on having groin injuries as the main objective (first priority) or the latest publication of the study cohort data (second priority), (3) studies with no available abstract, (4) studies published in journals without peer-review, (5) studies conducted in only one football club or team, (6) studies conducted on youth football, (7) studies conducted on indoor football (including futsal), (8) studies reporting injury data only for acute groin injuries or specific sub-types of groin injury (e.g. only adductor injuries), and (9) studies on multiple sports where no football specific injury data could be extracted.

\section{Risk of bias assessment}

A five-item study checklist was developed specifically for this review to assess the risk of bias in the included studies. The five items were based on the "Strengthening the reporting of observational studies in epidemiology" (STROBE) statement:[7] (1) study setting, location and study period, (2) eligibility criteria, and sources and methods of participant selection, (3) exposure definition and measurement, (4) study outcome definition and measurement, and (5) main result and precision (e.g. 95\% confidence interval). The studies were assessed as having 
a low or high risk of bias for each item. For all items, studies were assessed as having a high risk of bias if reporting was lacking or unclear. Additional examples for assessment of high risk of bias for each item are presented in supplementary table 1. Two authors (MW and MH) assessed the included articles independently and disagreements were resolved via consensus. No study was excluded based on the risk of bias assessment.

\section{Data extraction}

We developed a standardised data extraction sheet where the following injury data, if available, were extracted from the studies meeting the inclusion criteria: (1) the absolute number of groin injuries (including injuries to the groin and hip) and the total number of injuries, (2) the percentage of groin injury from all recorded injuries, and (3) the overall rate of groin injury (expressed as the number groin injuries/1000 h). In addition, general information on study characteristics (authors, publication year, and country of origin), characteristics of the study population (number of players, sex, and setting), study design, injury definition, and exposure to football (study period, number of team-seasons, and total player-exposure hours) was extracted from each study. The first author (MW) extracted all data which were checked by the second author $(\mathrm{MH})$. If the rate of groin injury rate was not presented in the article, this was calculated by the authors of this review as "number of groin injuries / total player-exposure hours x 1000”. The authors also calculated 95\% confidence intervals $(\mathrm{CI})$ for the injury rates to provide an estimate precision for each individual study.

\section{Quantitative synthesis}

To compare the relative groin injury proportion (percentage of all injuries) and the rate of groin injury rate between men and women, we aggregated the number of groin injuries, the total number of injuries, and the total player-exposure hours for all studies (where data were 
available) to a summary score. The absolute difference in relative groin injury proportion is reported with a $95 \% \mathrm{CI}$ and significance tested using z-statistics. The rate of groin injury was compared between sexes with a rate ratio (RR), presented with $95 \% \mathrm{CI}$, and significance tested using z-statistics. Both tests were two-tailed and a p-value $<0.05$ was accepted as statistically significant. 


\section{RESULTS}

A total of 34 studies were included in this review (figure 1). The literature search yielded 611 citations; after adjusting for duplicates 319 remained for the three-staged screening. Of these, 305 were discarded after reviewing the titles and abstracts. Full texts were retrieved for the remaining 14 studies which were examined in detail; six of these met the study inclusion criteria. In addition, 13 studies meeting the study criteria were identified in the reference lists of these selected six articles, and another 15 studies were identified through review of the authors' bibliographies. These 28 additional studies were all general injury surveillance studies that included estimates of groin injury rates within the body of the main text.

\section{Risk of bias assessment}

All 34 included studies were assessed for risk of bias (supplementary table 1). There were discrepancies between the two reviewers on 9 articles; all these discrepancies were resolved via consensus discussion without the need for involving the third author. Most frequently, the discrepancies were for item 3 (in five articles), which assessed the definition and measurement of exposure.

The vast majority of the included studies accurately reported and were assessed as having a low risk of bias regarding study setting, location and study period (33 articles), and on study outcome definition (injury) and measurement (31 articles). However, approximately half of the studies were assessed to have a high risk of bias regarding eligibility criteria, and sources and methods of participant selection (18 articles), exposure definition and measurement (17 articles), and main result and precision (16 articles). 
Two studies were assessed as having a low risk of bias for one item, seven studies for two items, eight studies for three items, ten studies for four items, and seven studies for all five items. There was a trend towards more low risk of bias items in newer publications where, for example, all articles published in the 1980s and 1990s scored low (two items) and all studies with four or five items assessed as having low risk of bias were published in 2004 or later.

\section{Groin injury frequency in men's club football}

We identified 20 studies that reported data on groin injury for at least one season in men's club football (table 1).[8-27] One study reported on both men's and women's elite football.[20] One study defined injury according to a combination of medical attention and time-loss.[21] All other studies included injuries according to various time-loss definitions; an injured player had to miss at least one future training session or match, $[8,13,14,19,20,27]$ the next training session or match,[11,12,17,18,26] missed the next day,[9,10,15,24,25] missed the next two days,[16] or was not specified.[19,20] All in all, the proportion of groin injury was between $4 \%$ and $19 \%$ of all injuries.

\section{Insert table 1 near here}

All studies were conducted in different European countries. Fourteen studies comprised one season and six included a varying number of consecutive seasons. Thirteen studies included the highest domestic playing level (division I) in their dataset. One study reported inclusion of professional level teams, but the exact playing levels were unclear from that study.

\section{Groin injury frequency in women's club football}

In addition to the study that reported on both men's and women's elite football,[20] we identified nine studies reporting groin injury data in women's club football (table 2).[28-36] 
These studies defined injury according to time-loss; an injured player had to miss at least one future training session or match,[28,34,36] the next training session or match,[31,32,35] missed the next day, $[29,33]$ or was removed from play or missed at least one future training session or match.[30] All in all, the proportion of groin injury was between $2 \%$ and $11 \%$ of all injuries.

\section{Insert table 2 near here}

All studies on women's football were carried out in Europe (Sweden, Norway and Germany) and they followed one season each. Eight studies included the highest domestic playing level (division I) in their dataset.

\section{Groin injury frequency in international tournaments}

We identified five studies conducted on international tournaments such as World Cups, European Championships and Olympic Games (table 3).[37-41] In the two studies investigating both men's and women's tournaments the percentage of groin injury was 5-11\% and $0-2 \%$, respectively.[40,41] In studies reporting both medical attention and expected timeloss injuries (only men's tournaments), the proportion of groin injury was 3-6\% and 5-9\%, respectively.[37-39]

Insert table 3 near here

\section{Rate of groin injury in men's and women's club football}

The reported and re-calculated rates of groin injury for 23 of the studies are summarised in table 4 . The rates varied from $0.2-2.1 / 1000 \mathrm{~h}$ in men's and 0.1-0.6/1000 $\mathrm{h}$ in women's club football. No trend towards an increase or decrease in the rate of groin injury over time was seen in one study spanning over seven consecutive seasons.[27] 


\section{Quantitative synthesis}

Based on aggregated data from all 29 studies of club football (tables 1 and 2), the relative proportion of groin injury in men (2716 of 21169) was higher than in women (126 of 1830), representing $12.8 \%$ vs. $6.9 \%$ of all reported injuries (absolute difference $5.9 \%, 95 \%$ CI $4.6 \%$ to $7.1 \%, \mathrm{p}<0.001)$. Similarly, based on aggregated data from the 23 studies where injury and exposure data were retrievable (1881 injuries and $2254420 \mathrm{~h}$ in men; 115 injuries and 330431 $\mathrm{h}$ in women), the rate of groin injury was more than two-fold higher in men than in women (0.83 vs. $0.35 / 1000$ h, RR $2.4,95 \%$ CI 2.0 to $2.9, \mathrm{p}<0.001)$. 


\section{DISCUSSION}

The principal finding of the current review was that groin injury constitutes a substantial problem in both men's and women's senior football. According to the 34 identified articles, however, groin injury appears to be a bigger problem in men than in women.

\section{Frequency of groin injury}

The vast majority of the included injury surveillance studies used a time-loss injury definition, and approximately every eighth (men) to fourteenth (women) time-loss injury was located to the groin. Many groin injuries, however, are a result of overuse leading to pain, and/or reduced performance, but may not cause time off from play, meaning that that the groin injury dilemma in football is likely to be underestimated.[42] Interestingly, the frequency of groin injury appears to be lower in international tournaments compared with most of the clubseason surveillance studies. In addition, almost all medical attention groin injuries registered during tournaments were expected to cause time-loss from play. Consequently, whereas groin injury during a club-season often is a result of overuse, and thereby thought to represent a “tip-of-the-iceberg" phenomenon, the injuries sustained during a tournament are probably more acute with a higher relative amount leading to time-loss.

\section{Men's vs. women's football}

As shown in the current review, groin injury appears to be more frequent among male footballers compared with their female counterparts regardless of the injury definition, study design, setting and playing level. The proportion of groin injury during club-season play was 4-19\% (aggregated 12.8\%) in men's football and 2-11\% (aggregated 6.9\%) in women's football, suggesting that groin injury comprises a bigger proportion of the total injury burden in male footballers. Since these figures do not take player-exposure into consideration, we 
also evaluated the rate of groin injury (injuries/1000 h) between sexes, which showed similar results. In the current review, the rates ranged from 0.2 to $2.1 / 1000 \mathrm{~h}$ in males and 0.1 to $0.6 / 1000 \mathrm{~h}$ in females, and the aggregated data indicated a 2.4 higher rate of groin injury in males. Groin injury in male footballers might thus be considered to constitute a reverse gender bias phenomenon compared with the anterior cruciate ligament dilemma in football, which is indisputably bigger in female players.[43] Although not determinable from the current review, possible reasons for this gender bias in groin injury rates might include both internal (e.g. differences in pelvic anatomy, muscle strength and force development, the occurrence of abdominal wall weakness/sportsman's hernia, etc.) and external factors (e.g. training and match load, playing intensity, etc.).

\section{Future directions}

Based on the current overview and risk of bias assessment in this critical review, it is clear that more (high-quality) research is needed in some areas. As advised by the PRISMA study group,[44] we would therefore suggest a few recommendations for future research. First, more studies reporting on the rate of groin injury with an accurate precision estimate are warranted, especially in women's football. Second, more studies with direct comparisons of injury frequencies and injury rates between the sexes are welcomed. Third, since many groin injuries are associated with overuse, and may not lead to lay-off during a club-season, more studies investigating problems of pain and/or reduced performance as a result of groin complaints not leading to time-loss are suggested.[45] Fourth, future studies on groin injury in football should preferably report detailed data for specific diagnoses or clinical entities as done in a few studies.[21,27] Fifth, all studies on women's football were carried out in Sweden, Norway and Germany, whereas the studies on men's football were more spread around Europe. In addition, most studies involved elite football cohorts. Thus, more studies 
are needed in other countries and continents, as well as in amateur and lower level football populations. Finally, although one study showed no apparent trend of increasing or decreasing injury rates over a 7-season period,[27] future studies with longer follow-ups and the possibility for time-trend analyses of injury risk are advocated.

\section{Methodological considerations}

Some limitations with the current review should be acknowledged. Most importantly, many injury surveillance studies reported the number and percentage of groin injury in the body of the articles only, and these injury data were rarely presented in the title or abstract. Consequently, many of the included articles were identified through the alternative search in the reference lists and in the authors' bibliographies. As a result, there is a risk that some general injury surveillance studies that would meet the inclusion criteria of the current review were missed in the literature screening. We performed no meta-analysis of included studies, and the aggregated injury proportions and injury rates presented in the review do not account for possible confounders, clustering effects, or the degree of heterogeneity within the results of the included studies. Another note is that the inclusion and exclusion criteria were slightly revised after the registration of the review in the PROSPERO register. Briefly, we decided to include only level I and II (prospective) studies, we added studies investigating international tournaments, and excluded studies reporting injury data only for acute groin injuries or specific sub-types of groin injury (e.g. muscle injuries). These changes from the original protocol should, however, have limited influence on the principal findings of the current review. Finally, since few studies report a clear definition of groin injury, and often report hip and groin injuries as a combined category as per the consensus statement for football injury surveillance,[46] we report on the occurrence of injury to the hip and groin combined in our literature overview and calculations. 


\section{Conclusion}

This comprehensive review on the epidemiology of groin injury in men's and women's senior football found that these injuries constitute between 7 to $13 \%$ of the injuries. Male football players had a more than two-fold higher rate of groin injury compared with female players. Few studies, however, report data for specific diagnoses or clinical entities, and future groin injury research in football needs also to be of higher study quality. 


\section{Acknowledgements}

We thank the hospital librarians Lone Heinlaid and Eva Karin Karlsson for their help with the literature search.

\section{Contributor statement}

All authors were responsible for the conception and design of the study. MW and MH searched the literature, extracted data and assessed risk of bias. JE was consulted if disagreements were not resolved by discussion. All authors contributed to the interpretation of findings and had full access to all data. MW wrote the first draft of the paper which was critically revised by the co-authors. The final manuscript has been approved by all authors.

\section{Funding}

The Football Research Group has been established in Linköping, Sweden, in collaboration with Linköping University and through grants from the Union of European Football Associations, the Swedish Football Association, the Football Association Premier League Limited, and the Swedish National Centre for Research in Sports.

\section{Competing interests}

None.

\section{Ethics approval}

Not relevant.

\section{Provenance and peer review}

Not commissioned; externally reviewed.

This paper is based on the authors' lectures in at the $1^{\text {st }}$ World Conference on Groin Pain in Athletes, Doha, Qatar, $1^{\text {st }}-3^{\text {rd }}$ November 2014. 


\section{WHAT ARE THE NEW FINDINGS?}

- Groin injury was a frequent occurrence in men's and women's senior football, comprising about 7 to $13 \%$ of all time-loss injuries.

- Groin injury was more frequent in men's football, with a more than two-fold higher rate identified in male compared with female players.

- Few studies report detailed data for specific diagnoses or clinical entities, and this should preferably be included in future studies on groin injury in football. 


\section{REFERENCES}

1. Fédération Internationale de Football Association. FIFA Big Count 2006: 270 million people active in football. http://www.fifa.com/aboutfifa/media/newsid=529882.html. Accessed December 22, 2010.

2. Junge A, Dvorak J. Soccer injuries: a review on incidence and prevention. Sports Med 2004;34:929-38.

3. Wong P, Hong Y. Soccer injury in the lower extremities. Br J Sports Med 2005;39:47382.

4. Agel J, Evans TA, Dick R, et al. Descriptive epidemiology of collegiate men's soccer injuries: National Collegiate Athletic Association Injury Surveillance System, 19881989 through 2002-2003. J Athl Train 2007;42:270-7.

5. Dick R, Putukian M, Agel J, et al. Descriptive epidemiology of collegiate women's soccer injuries: National Collegiate Athletic Association Injury Surveillance System, 1988-1989 through 2002-2003. J Athl Train 2007;42:278-85.

6. Moher D, Liberati A, Tetzlaff J, et al. Preferred reporting items for systematic reviews and meta-analyses: PRISMA statement. BMJ 2009;339:b2535.

7. von Elm E, Altman DG, Egger M, et al. Strengthening the reporting of observational studies in epidemiology (STROBE) statement: guidelines for reporting observational studies. BMJ 2007;335:806-8.

8. Árnason À, Sigurdsson SB, Gudmundsson A, et al. Risk factors for injuries in football. Am J Sports Med 2004;32:S5-S16.

9. aus der Fünten K, Faude O, Lensch J, et al. Injury characteristics in the German professional male soccer leagues after a shortened winter break. J Athl Train 2014;49:786-93. 
10. Bjørneboe J, Bahr R, Andersen TE. Gradual increase in the risk of match injury in Norwegian male professional football: a 6-year prospective study. Scand J Med Sci Sports 2014;24:189-96.

11. Ekstrand J, Gillquist J. Soccer injuries and their mechanisms: a prospective study. Med Sci Sports Exerc 1983;15:267-70.

12. Ekstrand J, Hilding J. The incidence and differential diagnosis of acute groin injuries in male soccer players. Scand J Med Sci Sports 1999;9:98-103.

13. Engebretsen AH, Myklebust G, Holme I, et al. Intrinsic risk factors for groin injuries among male soccer players: a prospective cohort study. Am J Sports Med 2010;38:20517.

14. Engström B, Forssblad M, Johansson C, et al. Does a major knee injury definitely sideline an elite soccer player? Am J Sports Med 1990;18:101-5.

15. Hawkins RD, Fuller CW. A prospective epidemiological study of injuries in four English professional football clubs. Br J Sports Med 1999;33;196-203.

16. Hawkins RD, Hulse MA, Wilkinson C, et al. The association football medical research programme: an audit of injuries in professional football. Br J Sports Med 2001;35:43-7.

17. Hägglund M, Waldén M, Ekstrand J. Injury incidence and distribution in elite football a prospective study of the Danish and the Swedish top divisions. Scand J Med Sci Sports $2005 ; 15: 21-8$

18. Hägglund M, Waldén M, Ekstrand J. Previous injury as a risk factor for injury in elite football: a prospective study over two consecutive seasons. Br J Sports Med 2006;40:767-72.

19. Hägglund M, Waldén M, Ekstrand J. Lower re-injury rate with a coach-controlled rehabilitation program in amateur male soccer: a randomized controlled trial. Am J Sports Med 2007;35:1433-42. 
20. Hägglund M, Waldén M, Ekstrand J. Injuries among male and female elite football players. Scand J Med Sci Sports 2009;19:819-27.

21. Hölmich P, Thorborg K, Dehlendorff C, et al. Incidence and clinical presentation of groin injuries in sub-elite soccer. Br J Sports Med 2014;48:1245-50.

22. Noya Salces J, Gómez-Carmona PM, Gracia-Marco L, et al. Epidemiology of injuries in First Division Spanish football. J Sports Sci 2014;32:1263-70.

23. Noya Salces J, Gómez-Carmona PM, Moliner-Urdiales D, et al. An examination of injuries in Spanish Professional Soccer League. J Sports Med Phys Fitness 2014;54:76571.

24. Sousa P, Rebelo A, Brito J. Injuries in amateur soccer players on artificial turf: a oneseason prospective study. Phys Ther Sport 2013;14:146-51.

25. van Beijsterveldt AMC, Stubbe JH, Schmikli SL, et al. Differences in injury risk and characteristics between Dutch amateur and professional soccer players. J Sci Med Sport 2014, http://dx.doi.org/10.1016/j.jsams.2014.02.004

26. Waldén M, Hägglund M, Ekstrand J. Injuries in Swedish elite football - a prospective study on injury definitions, risk for injury and injury pattern during 2001. Scand J Med Sci Sports 2005;15:118-25.

27. Werner J, Hägglund M, Waldén M, et al. UEFA injury study: a prospective study of hip and groin injuries in professional football over seven consecutive seasons. Br J Sports Med 2009;43:1036-40.

28. Engström B, Johansson C, Törnkvist H. Soccer injuries among elite female players. Am J Sports Med 1991;19:372-5.

29. Faude O, Junge A, Kindermann W, et al. Injuries in female soccer players: a prospective study in the German national league. Am J Sports Med 2005;33:1694-1700. 
30. Gaulrapp H, Becker A, Walther M, et al. Injuries in women's soccer: a 1-year all players prospective field study of the women's Bundesliga (German Premier League). Clin J Sport Med 2010;20:264-71.

31. Jacobson I, Tegner Y. Injuries among female football players - with special emphasis on regional differences. Adv Physiother 2006;8:66-74.

32. Jacobson I, Tegner Y. Injuries among Swedish female elite football players: a prospective population study. Scand J Med Sci Sports 2007;17:84-91.

33. Nilstad A, Andersen TE, Bahr R, et al. Risk factors for lower extremity injuries in elite female soccer players. Am J Sports Med 2014;42:940-8.

34. Söderman K, Alfredson, Pietilä T, et al. Risk factors for leg injuries in female soccer players: a prospective investigation during one out-door season. Knee Surg, Sports Traumatol, Arthrosc 2001;9:313-21.

35. Tegnander A, Olsen OE, Tegdan Moholdt T, et al. Injuries in Norwegian female elite soccer: a prospective one-season cohort study. Knee Surg Sports Traumatol Arthrosc 2008;16:194-8.

36. Östenberg A, Roos H. Injury risk factors in female European football: a prospective study of 123 players during one season. Scand J Med Sci Sports 2000;10:279-85.

37. Dvorak J, Junge A, Grimm K, et al. Medical report from the 2006 FIFA World Cup Germany. Br J Sports Med 2007;41:578-81.

38. Dvorak J, Junge A, Derman W, et al. Injuries and illnesses of football players during the 2010 FIFA World Cup. Br J Sports Med 2011;45:626-30.

39. Junge A, Dvorak J, Graf-Baumann T. Football injuries during the World Cup 2002. Am J Sports Med 2004;32:S23-7.

40. Junge A, Langevoort G, Pipe A, et al. Injuries in team sport tournaments during the 2004 Olympic Games. Am J Sports Med 2006;34:565-76. 
41. Waldén M, Hägglund M, Ekstrand J. Football injuries during European Championships 2004-2005. Knee Surg Sports Traumatol Arthrosc 2007;15:1155-62.

42. Bahr R. No injuries, but plenty of pain? On the methodology for recording overuse symptoms in sports. Br J Sports Med 2009;43:966-72.

43. Waldén M, Hägglund M, Werner J, et al. The epidemiology of anterior cruciate ligament injury in football (soccer): a review of the literature from a gender-related perspective. Knee Surg Sports Traumatol Arthrosc 2011;19:3-10.

44. Liberati A, Altman DG, Tetzlaff J, et al. The PRISMA statement for reporting systematic reviews and meta-analyses of studies that evaluate healthcare interventions: explanation and elaboration. BMJ 2009;339:b2700.

45. Clarsen B, Rønsen O, Myklebust G, et al. The Oslo Sports Trauma Research Center questionnaire on health problems: a new approach to prospective monitoring of illness and injury in elite athletes. Br J Sports Med 2014;48:754-60.

46. Fuller CW, Ekstrand J, Junge A, et al. Consensus statement on injury definitions and data collection procedures in studies of football (soccer) injuries. Br J Sports Med 2006;40-3:193-201. 


\section{TABLE AND FIGURE LEGENDS}

Table 1 Groin injury frequency in prospective studies of men's club football

Table 2 Groin injury frequency in prospective studies of women's club football

Table 3 Groin injury frequency in prospective studies of international tournaments in men's and women's football

Table 4 Rate of groin injury (injuries/1000 h) in prospective studies of men's and women's club football

Figure 1 Flow chart of literature search 
Table 1 Groin injury frequency in prospective studies of men's club football

\begin{tabular}{|c|c|c|c|c|c|c|c|c|}
\hline Study & Publication year & Country & Setting & Season(s) & No. of team-seasons & No. of players & Total no. of injuries & No. of groin injuries (\%) \\
\hline Árnason et al., 2004 & 2004 & Iceland & Divisions I and II & 1 season, 1999 & 17 & 306 & 244 & $32(13)$ \\
\hline aus der Fünten et al., 2014 & 2014 & Germany & Divisions I and II & 2 spring seasons, 2008 to 2010 & 14 & 254 & 300 & $12(4)$ \\
\hline Bjørneboe et al., 2014 & 2014 & Norway & Division I & 6 seasons, 2002 to 2007 & 73 & Unknown & 2325 & $255(11)$ \\
\hline Ekstrand \& Gillquist, 1983 & 1983 & Sweden & Division IV & 1 season, 1980 & 12 & 180 & 256 & $32(13)$ \\
\hline Ekstrand \& Hilding, 1999 & 1999 & Sweden & Division IV & 2 seasons, 1995 to 1996 & 21 & 326 & 382 & $31(8)$ \\
\hline Engebretsen et al., 2010 & 2010 & Norway & Division I to III & 1 season, 2004 & 31 & 508 & 505 & $61(12)$ \\
\hline Engström et al., 1990 & 1990 & Sweden & Divisions I and II & 1 season, 1987 & 3 & 64 & 85 & $10(12)$ \\
\hline Hawkins \& Fuller, 1999 & 1999 & United Kingdom & Amateur* & 3 seasons, 1994 to 1997 & 12 & 108 & 578 & $62(11)$ \\
\hline Hawkins et al., 2001 & 2001 & United Kingdom & Divisions I to IV & 2 seasons, 1997 to 1999 & 182 & 2376 & 6030 & $731(12)$ \\
\hline Hägglund et al., 2005 & 2005 & Denmark & Division I & 1 spring season, 2001 & 8 & 188 & 395 & $58(15)$ \\
\hline Hägglund et al., 2006 & 2006 & Sweden & Division I & 1 season, 2002 & 12 & 262 & 588 & $110(19)$ \\
\hline Hägglund et al., 2007 & 2007 & Sweden & Division IV & 1 season, 2003 & $10 \dagger$ & 241 & 134 & $12(9)$ \\
\hline Hägglund et al., 2009 & 2009 & Sweden & Division I & 1 season, 2005 & 11 & 239 & 548 & $97(18)$ \\
\hline Hölmich et al., 2014 & 2014 & Denmark & Division V to VII & 1 season, 2004 & 44 & 998 & 494 & $58(12)$ \\
\hline Noya Salces et al., 2014a & 2014 & Spain & Division I & 1 season, $2008 / 2009$ & 16 & 427 & 1293 & $175(14)$ \\
\hline Noya Salces et al., 2014b & 2014 & Spain & Division II & 1 season, 2008 to 2009 & 11 & 301 & 891 & $144(16)$ \\
\hline Sousa et al., 2013 & 2013 & Portugal & Amateur* & 1 season, 2010 to 2011 & 11 & 231 & 213 & $17(8)$ \\
\hline \multirow[t]{2}{*}{ van Beijsterveldt et al., 2014} & 2014 & The Netherlands & Division I & 1 season, 2009 to 2010 & 8 & 217 & 286 & $30(10)$ \\
\hline & & & Amateur* & 1 season, 2009 to 2010 & 23 & 456 & 424 & $47(11)$ \\
\hline Waldén et al., 2005 & 2005 & Sweden & Division I & 1 season, 2001 & 14 & 310 & 715 & $114(16)$ \\
\hline Werner et al., 2009 & 2009 & Europe: & Division I & 7 seasons, 2001 to 2008 & 23 & 1065 & 4483 & $628(14)$ \\
\hline
\end{tabular}


*The exact playing level of included clubs was not defined in the study

$\dagger$ Only control group teams included from a randomised trial.

† Belgium, France, Germany, Italy, the Netherlands, Portugal, Scotland, Spain, Ukraine and United Kingdom. 
Table 2 Groin injury frequency in prospective studies of women's club football

\begin{tabular}{|c|c|c|c|c|c|c|c|c|}
\hline Study & Publication year & Country & Setting & Season(s) & No. of team-seasons & No. of players & Total no. of injuries & No. of groin injuries (\%) \\
\hline Engström et al., 1991 & 1991 & Sweden & Divisions I and II & 1 season, 1988 & 2 & 41 & 78 & $5(6)$ \\
\hline Faude et al., 2005 & 2005 & Germany & Division I & 1 season, 2003/2004 & 9 & 165 & 241 & $15(6)$ \\
\hline Gaulrapp et al., 2010 & 2010 & Germany & Division I & 1 season, $2004 / 2005$ & 12 & 254 & 246 & $4(2)$ \\
\hline Hägglund et al., 2009 & 2009 & Sweden & Division I & 1 season, 2005 & 12 & 228 & 299 & $34(11)$ \\
\hline Jacobson \& Tegner, 2006 & 2006 & Sweden & Division II & 1 season, 1998 & 18 & 253 & 229 & $11(5)$ \\
\hline Jacobson \& Tegner, 2007 & 2007 & Sweden & Division I & 1 season, 2000 & 9 & 159 & 232 & $17(7)$ \\
\hline Nilstad et al., 2014 & 2014 & Norway & Division I & 1 season, 2009 & 12 & 173 & 171 & $14(8)$ \\
\hline Söderman et al., 2001 & 2001 & Sweden & Division II and III & 1 season, 1998 & 13 & 146 & $80 *$ & $4(5)$ \\
\hline Tegnander et al., 2008 & 2008 & Norway & Division I & 1 season, 2001 & 10 & 181 & 189 & $17(9)$ \\
\hline Östenberg \& Roos, 2000 & 2000 & Sweden & Division I to $\mathrm{V}$ & 1 season, 1996 & 8 & 123 & 65 & $5(8)$ \\
\hline
\end{tabular}

*Only injuries of the lower limbs. 
Table 3 Groin injury frequency in prospective studies of international tournaments in men's and women's football

\begin{tabular}{|c|c|c|c|c|c|c|c|c|c|}
\hline Study & Publication year & Country & Sex & Tournament(s) & No. of teams & No. of players & Injury definition & Total no. of injuries & No. of groin injuries (\%) \\
\hline \multirow[t]{2}{*}{ Dvorak et al., 2007} & 2007 & Germany & Male & World Cup, 2006 & 32 & 736 & Medical attention & $145^{*}$ & $7(5)$ \\
\hline & & & & & & & Expected time-loss & $97^{*}$ & $5(5)$ \\
\hline \multirow[t]{2}{*}{ Dvorak et al., 2011} & 2011 & South Africa & Male & World Cup, 2010 & 32 & 736 & Medical attention & 229 & $7(3)$ \\
\hline & & & & & & & Expected time-loss & 144 & $7(5)$ \\
\hline \multirow[t]{2}{*}{ Junge et al., 2004} & 2004 & Korea and Japan & Male & World Cup, 2002 & 32 & 704 & Medical attention & $171^{*}$ & $11(6)$ \\
\hline & & & & & & & Expected time-loss & $107 *$ & $10(9)$ \\
\hline \multirow[t]{2}{*}{ Junge et al., 2006} & 2006 & Greece & Male & Olympic Games, 2004 & 16 & 288 & Medical attention & 77 & $4(5)$ \\
\hline & & & Female & Olympic Games, 2004 & 10 & 180 & Medical attention & 45 & $1(2)$ \\
\hline \multirow[t]{2}{*}{ Waldén et al., 2007} & 2007 & Portugal & Male & European Championship, 2004 & 16 & 368 & Time-loss & 45 & $5(11)$ \\
\hline & & United Kingdom & Female & European Championship, 2005 & 8 & 160 & Time-loss & 18 & 0 \\
\hline
\end{tabular}

*Only match injuries. 
Table 4 Rate of groin injury (injuries/1000 h) in prospective studies of men's and women's club football

\begin{tabular}{|c|c|c|c|c|c|}
\hline Study & Sex & Setting & Injury definition & No. of groin injuries & Rate of groin injury ( $95 \% \mathrm{CI})$ \\
\hline Árnason et al., 2004 & Male & Divisions I and II & Time-loss & 32 & $0.9^{*}(0.7$ to 1.3$)$ \\
\hline aus der Fünten et al., 2014 & Male & Divisions I and II & Time-loss & 12 & $0.2^{*}(0.1$ to 0.4$)$ \\
\hline Bjørneboe et al., 2014 & Male & Division I & Time-loss & 255 & $0.5^{*}(0.5$ to 0.6$)$ \\
\hline Ekstrand \& Hilding, 1999 & Male & Division IV & Time-loss & 31 & $0.8(0.6$ to 1.1$)$ \\
\hline Engebretsen et al., 2010 & Male & Division I to III & Time-loss & 61 & $0.6(0.4$ to 0.7$)$ \\
\hline Faude et al., 2005 & Female & Division I & Time-loss & 15 & $0.4^{*}(0.3$ to 0.7$)$ \\
\hline Gaulrapp et al., 2010 & Female & Division I & Time-loss & 4 & $0.1 *(0.0$ to 0.1$)$ \\
\hline Hägglund et al., 2005 & Male & Division I & Time-loss & 58 & $2.1 *(1.6$ to 2.7$)$ \\
\hline Hägglund et al., 2006 & Male & Division I & Time-loss & 110 & $1.4^{*}(1.2$ to 1.7$)$ \\
\hline Hägglund et al., 2007 & Male & Division IV & Time-loss & 12 & $0.5^{*}(0.3$ to 0.8$)$ \\
\hline \multirow[t]{2}{*}{ Hägglund et al., 2009} & Male & Division I & Time-loss & 97 & $1.4^{*}(1.1$ to 1.7$)$ \\
\hline & Female & Division I & Time-loss & 34 & $0.6^{*}(0.4$ to 0.9$)$ \\
\hline Hölmich et al., 2014 & Male & Amateur $\dagger$ & Combined $\ddagger$ & 58 & $0.4(0.3$ to 0.5$)$ \\
\hline Jacobson \& Tegner, 2006 & Female & Division II & Time-loss & 11 & $0.5(0.3$ to 0.8$)$ \\
\hline Jacobson \& Tegner, 2007 & Female & Division I & Time-loss & 16 & $0.3(0.2$ to 0.5$)$ \\
\hline Nilstad et al., 2014 & Female & Division I & Time-loss & 14 & $0.3 *(0.2$ to 0.5$)$ \\
\hline Noya Salces et al., 2014a & Male & Division I & Time-loss & 175 & $0.8(0.7$ to 0.9$)$ \\
\hline Noya Salces et al., 2014b & Male & Division II & Time-loss & 144 & $0.9^{*}(0.8$ to 1.0$)$ \\
\hline Sousa et al., 2013 & Male & Amateur $\dagger$ & Time-loss & 17 & $0.4^{*}(0.2$ to 0.6$)$ \\
\hline Söderman et al., 2001 & Female & Division II and III & Time-loss & 4 & $0.3^{*}(0.1$ to 0.7$)$ \\
\hline Tegnander et al., 2008 & Female & Division I & Time-loss & 17 & $0.6^{*}(0.3$ to 0.9$)$ \\
\hline \multirow[t]{2}{*}{ van Beijsterveldt et al., 2014} & Male & Division I & Time-loss & 30 & $0.6^{*}(0.5$ to 0.9$)$ \\
\hline & Male & Amateur $\dagger$ & Time-loss & 47 & $1.1^{*}(0.8$ to 1.4$)$ \\
\hline Waldén et al., 2005 & Male & Division I & Time-loss & 114 & $1.2 *(1.0$ to 1.5$)$ \\
\hline Werner et al., 2009 & Male & Division II & Time-loss & 628 & $1.1(1.0$ to 1.2$)$ \\
\hline
\end{tabular}

CI, confidence interval

*Rate of groin injury recalculated by the authors of this review based on exposure and injury data presented in the study.

$\dagger$ The exact playing level of included clubs was not defined in the study

†The injury definition was a combination of medical attention and time-loss. 


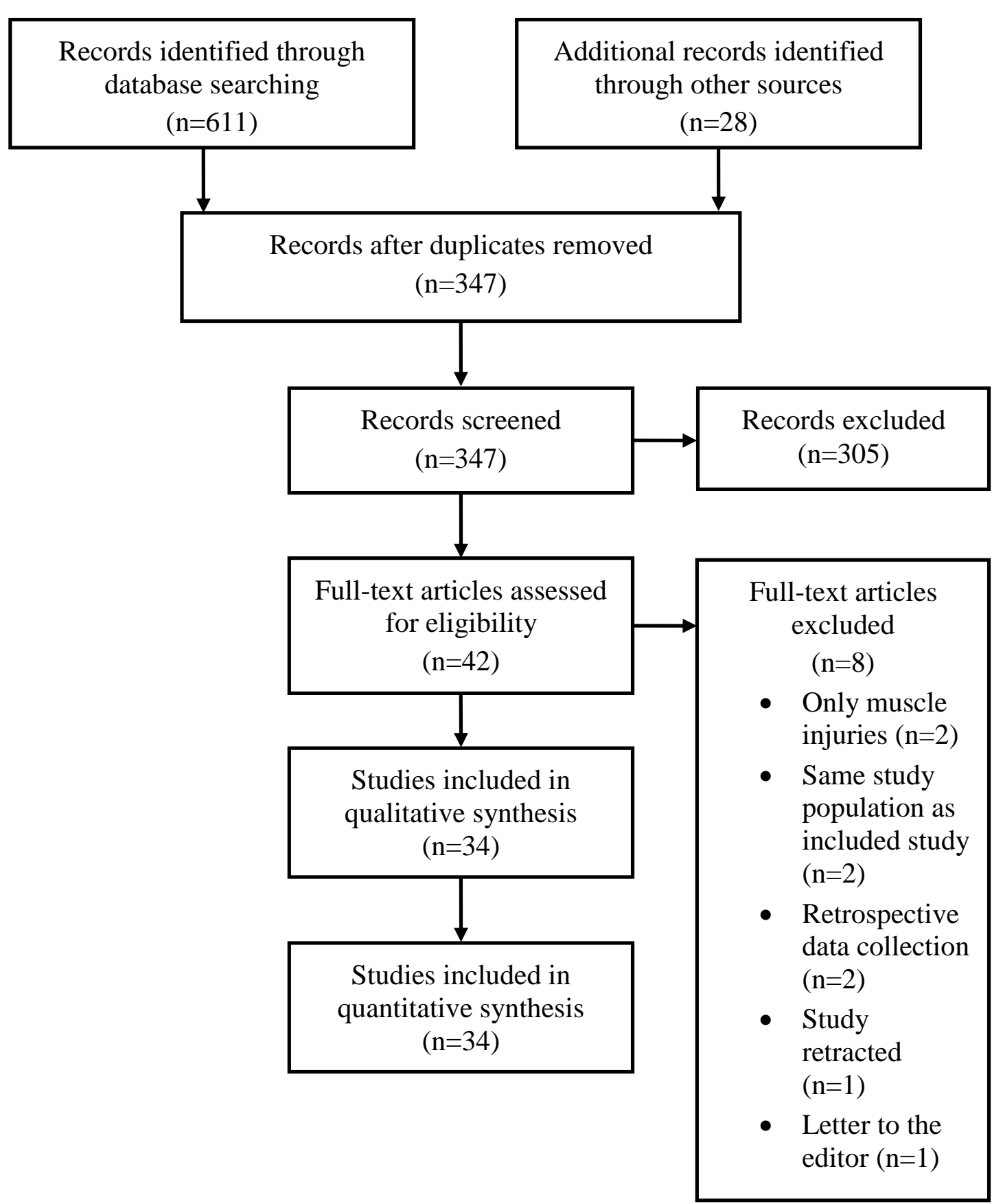

Figure 1 Flow chart of literature search 
Supplementary table 1 The five-item study checklist used to assess risk of bias in the included studies.

\begin{tabular}{|c|c|c|c|c|c|c|}
\hline Included studies ( $\mathbf{N}=\mathbf{3 4}$ ) & $\begin{array}{l}\text { (1) study setting, location } \\
\text { and study period }\end{array}$ & $\begin{array}{l}\text { (2) eligibility criteria, } \\
\text { and sources and methods } \\
\text { of participant selection }\end{array}$ & $\begin{array}{l}\text { (3) exposure definition } \\
\text { and measurement }\end{array}$ & $\begin{array}{l}\text { (4) study outcome } \\
\text { definition and } \\
\text { measurement }\end{array}$ & $\begin{array}{l}\text { (5) main result and } \\
\text { precision (e.g. 95\% } \\
\text { confidence interval) }\end{array}$ & $\begin{array}{l}\text { No. of items with low risk } \\
\text { of bias }\end{array}$ \\
\hline Árnason et al., 2004 & 1 & 0 & 1 & 1 & 1 & 4 \\
\hline aus der Fünten et al., 2014 & 1 & 0 & 1 & 1 & 1 & 4 \\
\hline Bjørneboe et al., 2014 & 1 & 1 & 1 & 1 & 1 & 5 \\
\hline Dvorak et al., 2007 & 1 & 1 & 0 & 1 & 0 & 3 \\
\hline Dvorak et al., 2011 & 1 & 1 & 0 & 1 & 0 & 3 \\
\hline Ekstrand \& Gillquist, 1983 & 1 & 0 & 0 & 1 & 0 & 2 \\
\hline Ekstrand \& Hilding, 1999 & 1 & 0 & 0 & 1 & 0 & 2 \\
\hline Engebretsen et al., 2010 & 1 & 0 & 1 & 1 & 1 & 4 \\
\hline Engström et al., 1990 & 1 & 0 & 0 & 1 & 0 & 2 \\
\hline Engström et al., 1991 & 1 & 0 & 0 & 1 & 0 & 2 \\
\hline Faude et al., 2005 & 1 & 0 & 1 & 1 & 1 & 4 \\
\hline Gaulrapp et al., 2010 & 1 & 1 & 0 & 1 & 0 & 3 \\
\hline Hawkins \& Fuller, 1999 & 1 & 0 & 0 & 1 & 0 & 2 \\
\hline Hawkins et al., 2001 & 1 & 1 & 0 & 1 & 0 & 3 \\
\hline Hägglund et al., 2005 & 1 & 0 & 1 & 1 & 1 & 4 \\
\hline Hägglund et al., 2006 & 1 & 1 & 1 & 1 & 1 & 5 \\
\hline Hägglund et al., 2007 & 1 & 1 & 1 & 1 & 1 & 5 \\
\hline Hägglund et al., 2009 & 1 & 1 & 1 & 1 & 1 & 5 \\
\hline Hölmich et al., 2014 & 1 & 0 & 1 & 1 & 1 & 4 \\
\hline Jacobson \& Tegner, 2006 & 1 & 0 & 0 & 1 & 0 & 2 \\
\hline Jacobson \& Tegner, 2007 & 1 & 1 & 0 & 1 & 0 & 3 \\
\hline
\end{tabular}




\begin{tabular}{|c|c|c|c|c|c|c|}
\hline Junge et al., 2004 & 1 & 1 & 0 & 1 & 0 & 3 \\
\hline Junge et al., 2006 & 1 & 1 & 0 & 1 & 1 & 4 \\
\hline Nilstad et al., 2014 & 1 & 0 & 1 & 1 & 1 & 4 \\
\hline Noya Salces et al., 2014a & 1 & 1 & 0 & 0 & 1 & 3 \\
\hline Noya Salces et al., 2014b & 1 & 0 & 0 & 0 & 0 & 1 \\
\hline Sousa et al., 2013 & 0 & 0 & 1 & 1 & 1 & 3 \\
\hline Söderman et al., 2001 & 1 & 0 & 0 & 0 & 0 & 1 \\
\hline Tegnander et al., 2008 & 1 & 1 & 1 & 1 & 0 & 4 \\
\hline van Beijsterveldt et al., 2014 & 1 & 0 & 1 & 1 & 1 & 4 \\
\hline Waldén et al., 2005 & 1 & 1 & 1 & 1 & 1 & 5 \\
\hline Waldén et al., 2007 & 1 & 1 & 1 & 1 & 1 & 5 \\
\hline Werner et al., 2009 & 1 & 1 & 1 & 1 & 1 & 5 \\
\hline Östenberg \& Roos, 2000 & 1 & 0 & 0 & 1 & 0 & 2 \\
\hline
\end{tabular}

The five items were based on the "Strengthening the reporting of observational studies in epidemiology" (STROBE) statement (von Elm et al., 2007), and for each item the studies were assessed as having a low risk (1) or high risk (0) of bias. For all items, studies were assessed as having a high risk of bias if reporting was lacking or unclear. Specific examples for assessment of high risk of bias for item 1 were: unclear reporting on the level of play for included teams/players; for item 2: unclear eligibility criteria, unclear selection, or biased selection of teams/players for inclusion (e.g. the best 15 players in a team), or large dropout ( $\geq 25 \%)$ of teams or players during study; for item 3: unclear football exposure registration, or approximated exposure to football; for item 4: unclear injury definition, or uncertainty regarding accuracy of measurement of injuries; and for item 5: unclear regarding number of groin injuries and/or rate of groin injury per 1000 hours, and precision estimate lacking. 